\title{
Grupos de interés de la responsabilidad social externa en la industria farmacéutica
}

\author{
Stakeholders of external social responsibility in the pharmaceutical industry
}

\section{Carla Goncalves}

goncalvescarlae@gmail.com

Código ORCID: 0000-0001-7959-4590

Universidad del Zulia, Venezuela

Articulo recibido en enero 2019
$<\quad$ Arbitrado en febrero 2019
$<$ Publicado en julio 2019

Resumen

El objetivo de esta investigación fue identificar los grupos de interés de la responsabilidad social externa presentes en la industria farmacéutica del estado ZuliaVenezuela. El tipo de investigación fue descriptiva, con diseño no experimental, de campo y transeccional, utilizándose como población las droguerías farmacéuticas del estado Zulia inscrita en la Cámara de Industriales del Estado Zulia. La técnica de recolección de datos fue el cuestionario, validado por el juicio de cinco (5) expertos y la confiabilidad medida por el coeficiente Alpha de Crombach, cuyo valor fue de 0,913 . Para el análisis de los datos se utiliza la estadística descriptiva a través del cálculo de la media aritmética. Se evidencia alta presencia en su Responsabilidad Social Externa de los consumidores, proveedores, competidores y gobierno, mientras, ostentaron mediana presencia lo referente a la comunidad y medio ambiente, como grupos de interés que permita promover la creación de una ciudadanía corporativa global.

Palabras clave: Competidores, comunidad, consumidores, gobierno, medio ambiente, proveedores y responsabilidad social externa

\begin{abstract}
The objective of this investigation was to identify the stakeholders of the external social responsibility present in the pharmaceutical industry of Zulia-Venezuela state. The type of research was descriptive, with a non-experimental, field and transectional design, using the pharmaceutical drugstores of the Zulia state registered in the Chamber of Industrialists of the Zulia State as a population. The data collection technique was the questionnaire, validated by the judgment of five (5) experts and the reliability measured by the Crombach Alpha coefficient, whose value was 0.913 . For the analysis of the data, descriptive statistics were used through the calculation of the arithmetic mean. There was a high presence in its External Social Responsibility of consumers, suppliers, competitors and government, while they had a medium presence in relation to the community and the environment, as interest groups that allow promoting the creation of a global corporate citizenship.
\end{abstract}

Keywords: Competitors, community, consumers, government, environment, suppliers and external social responsibility 


\section{INTRODUCCIÓN}

Actualmente, la importancia que las empresas tomen en cuenta las necesidades de la sociedad, así como del entorno en el cual se desenvuelven, para contar con la aceptación y confianza de la misma en las operaciones que realizan, contribuyendo en su bienestar; traduciéndose en mejor calidad de vida. Es necesario así, que las empresas adquieran una postura positiva en cuanto a la responsabilidad social empresarial, actuando más allá de sus propias metas de producción.

Dentro de este contexto, la integración de los mercados y la caída de las barreras comerciales representan para las empresas el desafío de mantenerse en niveles de competitividad y productividad, desafío que debe ir acompañado de una preocupación creciente por la legitimidad de su actuación social como también de su papel como constructora del bien común (Fernández, 2009).

Al respecto, la responsabilidad social empresarial debe ser vista como una estrategia para alcanzar beneficios externos e internos para las empresas, aunque está latente, hoy en día, cierto comportamiento dominante de rechazo hacia la responsabilidad social, lo cual obliga a fortalecer la investigación en este sentido, según lo afirma Navarro (2012).

Bajo esta perspectiva, al promover la empresa el bien común en la sociedad, está asegurando su viabilidad a largo plazo. Si contribuye al bien social, reduce los crecientes controles gubernamentales, la compañía debe comprender estas nuevas exigencias para las empresas y empresarios. Los cuales, hoy en día, deben tener autentico interés por la sociedad como algo fundamental en la conducta de los negocios mismos, esto exige que la calidad de vida se convierta en un asunto de las empresas.

En el caso de Venezuela, acota Rivera (2015), la responsabilidad social empresarial (RSE) se ha venido tratando principalmente en medianas y grandes empresas cuyos procesos tienen gran influencia en el medio ambiente y la comunidad; aunque algunos empresarios de diferentes sectores no le han dado la importancia y relevancia que el tema tiene no solo en el desarrollo económico de las regiones, sino en la imagen y competitividad de las empresas mismas.

Según el autor citado, la RSE al 2014 era un concepto informal y no una prioridad organizacional, por tanto son escasos los estudios que se tienen al respecto y los pocos que existen dan un diagnóstico general poco especificado en el que se encierra toda la industria, además no profundizan en los factores que realmente determinan el nivel de responsabilidad que las organizaciones tienen en el desarrollo de sus procesos, operaciones y la prestación de los servicios.

En el mismo orden de ideas, según González (2010), en Venezuela se ha documentado la existencia de actividades de interés social por parte de la empresa privada desde el siglo XIX. Sin embargo, la visión con la que se encaraba este tipo de actividades no correspondía con el concepto contemporáneo de RSE, sino que se veía como obras de filantropía voluntarias llevadas por los empresarios, especialmente aquéllos con mayor compromiso religioso o ético.

Desde ese momento, las prácticas socialmente responsables, los conceptos asociados y forma de integrarlos en la gestión de la empresa han ido cambiando, hasta llegar en el momento actual a un esquema en el cual, estas acciones son 
concebidas como inherentes al funcionamiento de la empresa, especialmente en el caso de las grandes empresas nacionales. No obstante, durante los últimos 20 años ha adquirido un mayor auge la responsabilidad social empresarial, tanto en su dimensión interna como en la externa, pues empresarios como gerentes ahora están más sensibles ante la verdadera magnitud de los problemas presentados en su empresa, ambiente y en la sociedad.

Cabe resaltar, en Venezuela, la Fundación Escuela de Gerencia Social (FEGS) (2015) ha diseñado una metodología para realizar un balance social. En este modelo, la responsabilidad social se divide en dos enfoques: interno y externo. El primero se refiere a la relación de la empresa con sus trabajadores, mientras que el segundo evalúa las relaciones con el entorno. El objetivo del modelo es integrar un conjunto de indicadores sobre estas dimensiones de forma tal que "... le permite a la empresa evaluar el alcance de sus objetivos sociales, información que sirve de complemento a la presentación de los resultados alcanzados en materia financiera" (Machado y otros 2012: p. 19).

Ahora bien, a objeto de esta investigación se siente un interés particular por conocer cómo se han ido estableciendo los grupos de interés de la responsabilidad social externa en las operaciones de la industria farmacéutica del estado Zulia, en específico en las droguerías establecidas en el municipio Maracaibo.

A este respecto, se aclara, estas empresas son encargadas de distribuir los medicamentos desde sus almacenes hasta los puntos de venta, es decir, adquieren los medicamentos de los laboratorios para luego venderlos a las farmacias (Federación
Farmacéutica Venezolana, 2006). Su existencia se debe a dos razones fundamentales, en primer término, por las distancias que existen entre los laboratorios a las farmacias, así como por el volumen de pedido de estas últimas a los laboratorios.

Específicamente, en el estado Zulia, existen cuatro droguerías, las cuales a través de entrevistas informales realizadas a gerentes, se pudo conocer que la responsabilidad social externa no se ha incluido adecuadamente dentro de su planificación estratégica, trayendo como efecto debilidades en los principios establecidos para una actuación responsable con el entorno. Esto puede deberse, a una escasa información de los gerentes sobre las acciones que pueden llevarse a cabo para cumplir con esta responsabilidad en beneficio de la sociedad, y agregar valor a las operaciones de la empresa en general.

Bajo esta óptica, surge la interrogante de conocer ¿Cuáles son los grupos de interés de la responsabilidad social externa presentes en la industria farmacéutica del estado Zulia? a fin de tomar en cuenta las acciones necesarias para facilitar el desarrollo efectivo de esta responsabilidad en las empresas reseñadas y así generar bienestar integral.

\section{Grupos de interés de la responsabilidad social externa}

Las organizaciones de hoy, para Gómez (2013), se encuentran sometidas a complejas presiones de diverso tipo $y$ diferentes grupos, incluso a conflictos de intereses que reclaman esfuerzos particulares. A esto se agrega que, las relaciones e impactos de la empresa no sólo son reconocibles en grupos de interés formalmente identificados, sino también sus efectos visibles se dejan sentir sobre 
entidades más genéricas, como son el crecimiento económico local, desarrollo de las comunidades y ambiente.

Ahora bien, acota este autor, las relaciones de las empresas con sus grupos de interés pueden apreciarse como círculos concéntricos de un mismo origen, donde considera pertinente una analogía con el capital social. Primero, se identifica un circulo de afinidad representado por personas del mismo parentesco $\circ$ de relaciones muy cercanas de amistad; segundo, un circulo de afiliación que comprende a las personas y grupos orientados hacia objetivos comunes e intereses conjugados por una determinada asociación; y tercero, un circulo de vinculación que remite a relaciones más abiertas y no inscritas en aspectos predeterminados por la sangre, afecto 0 asociatividad.

Pues bien, explica Martínez (2011), en sentido equivalente, podría hablarse de grupos de interés interno y externo, o más precisos se podría pensar en grupos internos, pertenecientes al entorno inmediato y del contexto. De esta forma, los grupos de interés internos son los que tienen relación directa con aspectos organizacionales y funcionales de la empresa (socios, accionistas, y trabajadores).

Los relativos al entorno inmediato representan una vinculación explicita con el negocio, en efecto, conforman su periferia estratégica (consumidores, proveedores, comunidad, competidores, gobierno, y medio ambiente). Finalmente, los grupos del contexto lo ocupan los vinculados en un segundo orden de resonancia (comunidades locales, administraciones públicas, entidades de interés social, derechos humanos, medios de comunicación, problemas ecológicos, grupos de opinión, organizaciones no gubernamentales y sociedad; público en general).

Los fenómenos de la imagen de una empresa proceden de la forma como el contexto percibe a la empresa, en cambio los relativos a la reputación provienen de la valoración y admiración que tiene el entorno, después de comparar a la empresa con el resto del mismo sector. También se destaca que, las relaciones establecidas entre los grupos de interés son dinámicas y complejas: todas se relacionan, y ninguna podría comprenderse fuera del marco de esas relaciones totalizadoras. Esta realidad hace que, al momento de diseñar una estrategia de RS, se tomen en consideración todas ellas.

Luego de esta disquisición, tomada de Gómez (2013) y Martínez (2011), se impone aclarar que a efectos de la investigación, como grupos de interés de la responsabilidad social externa se asumen los pertenecientes al entorno inmediato: consumidores, proveedores, comunidad, competidores, gobierno, y medio ambiente.

Al respecto, bajo el criterio de Fernández (2009), el alcance de la RSE significa indagar ante quien es responsable la empresa, por ello, debe ser responsabilidad de la empresa evaluar todos sus procesos de decisión así como sus efectos sobre los demás. Ésta debe observar a clientes, distribuidores y proveedores, pues mantiene una estrecha relación con ellos. Además, también está relacionada con otro contexto denominado la comunidad, en la cual se incluyen los ciudadanos, gobierno y empresas competidoras.

Es decir, comprende la investigadora, la responsabilidad principal de las empresas es generar beneficios, contribuyendo a su vez al logro de objetivos sociales $y$ 
medioambientales, integrando la responsabilidad social externa como inversión estratégica en el núcleo de su estrategia empresarial, sus instrumentos de gestión y sus actividades. Ahora bien, con base a los aportes de los autores consultados, se observa como éstos coinciden en asumir dos (2) grupos de interés en su responsabilidad social externa: los del entorno inmediato y los del contexto donde se encuentra inmersa la empresa.

Sin embargo, en las operaciones de las droguerías en la industria farmacéutica del estado Zulia se asumirán los grupos de interés del entorno inmediato: consumidores, proveedores, comunidad, competidores, gobierno y medio ambiente. Esta elección, en particular, corresponde al hecho de que son consideradas con mayor pertinencia en el estudio de la responsabilidad social externa de estas empresas.

\section{Consumidores}

Para Martínez (2011), la empresa existe gracias a los clientes o consumidores que logra desarrollar. La piedra angular de la mercadotecnia es muy simple: si hay clientes, hay empresa. En las economías de mercado, la responsabilidad para con los consumidores es requisito de supervivencia. Así, se deben satisfacer sus necesidades y expectativas para mantenerse en el mercado.

Por su parte afirma Gómez (2013), que lograr la aceptación de los clientes es de obvia importancia si el negocio espera obtener utilidades, debido a que los contratos con ellos, constituyen una parte importante de las operaciones comerciales, y suelen considerarse distintas. Sin embargo, estos constituyen el punto más difícil de la mayoría de las firmas.
En el mismo orden de ideas, Fernández (2009) afirma, la prosperidad de la empresa solo es posible si se satisface eficazmente una necesidad social, por ello se señala, claramente, que el verdadero jefe de la empresa, el árbitro final de sus actos es el consumidor. Él es quien obliga a tomar muchas decisiones desagradables para los hombres de la empresa, a exigir disciplina y orden a los trabajadores, buscar mejores y más baratos artículos, a reducir los márgenes, a no conceder aumentos imprudentes de sueldos o prestaciones, a asumir programas de desarrollo social, entre otros.

Al respecto, agrega este autor, son responsabilidades para los consumidores, en sus exigencias a la empresa, el mantenimiento de la calidad ofrecida, veracidad de atributos satisfactorios, cumplimiento de ofrecimientos y garantías, mejora continua de procesos, intensificación de la innovación para la mejora o diseño de los productos o servicios, interés por la satisfacción de sus necesidades o expectativas, tiempo de respuesta oportuno, entre otros.

Ahora bien, en el Libro Verde de la Comunidad Económica Europea (2001) citado por Calvo (2014), se plantea, como parte de su responsabilidad social externa las empresas deben ofrecer de manera eficaz, ética y ecológica productos o servicios que los consumidores necesitan o desean. Se espera que las empresas establezcan relaciones duraderas con sus clientes, centrando su organización en la comprensión de sus deseos, ofreciéndoles calidad, seguridad, fiabilidad y servicio superiores, así obtengan mayores beneficios.

Agrega esta obra, la puesta en práctica del principio según el cual los productos se 
diseñan pensando en que puedan ser utilizados por el mayor número de personas posible, incluidos los consumidores afectados por una discapacidad, es un ejemplo importante de la responsabilidad de las empresas en el ámbito social.

Bajo las premisas expuestas, la investigadora infiere, desde la sociedad civil se debe ver a la responsabilidad social externa de las empresas como oportunidad, una herramienta que asiente los derechos ciudadanos en general, entre ellos consumidores y usuarios, de manera de impulsar un desarrollo socialmente responsable, justo y sostenible.

Asimismo, la investigadora comprende, desde la posición de consumidores y usuarios, se le debe valorar como la posibilidad de lograr la colaboración de organizaciones de la sociedad civil que operan desde diferentes ámbitos, tanto en el plano nacional como internacional. Esto permite una interrelación importante para poder plantear líneas de trabajo que puedan confluir en un proyecto común; además, al trabajar de forma conjunta, estarán aportando una mayor visibilidad a todas las actuaciones y propuestas que desarrolle la empresa.

\section{Proveedores}

Según Navarro (2012), una entrada regular de material para un fabricante o de mercancía para un minorista son iguales en su contribución al éxito, por ello, la buena voluntad del proveedor es de capital importancia cuando hay escasez de materiales o de mercancías, si se desean condiciones liberales de compra, y cuando es necesaria la entrega rápida $u$ otro tratamiento especial. Así, son responsabilidades para con los proveedores, el cumplimiento de obligaciones (convenios, pagos) y mantener una conducta apegada a la veracidad e integridad.

En este sentido, afirma el autor citado, al colaborar estrechamente con sus socios comerciales, las empresas pueden reducir la complejidad, los costos y aumentar la calidad, por tanto, los proveedores no siempre se deben seleccionar mediante un procedimiento de concurso. Asimismo, se debe tomar en cuenta que las relaciones con los socios de alianzas y empresas de riesgo compartido son igualmente importantes.

A largo plazo, las relaciones establecidas pueden traducirse en precios, cláusulas y expectativas equitativas, suministros fiables $y$ de calidad. No obstante, cuando adoptan practicas responsables en el ámbito social y medioambiental, las empresas deben respetar tanto la legislación comunitaria como la normativa nacional en materia de competencia, de acuerdo a como lo indica Navarro (2012).

Para Gómez (2013), los proveedores son parte fundamental de una organización, pues proporcionan insumos que hacen posible los procesos de intercambio (servicio) o la transformación (industria). Con ellos es básico establecer una relación formal, basada en la confianza y en el cumplimiento. En los negocios modernos las relaciones con los proveedores son clave.

De acuerdo a Fernández (2009), las grandes empresas son al mismo tiempo socios comerciales de las empresas más pequeñas, sea en calidad de clientes, proveedores, subcontratistas o competidores. Las empresas deben ser conscientes de que sus resultados sociales pueden verse afectados por las prácticas de socios y proveedores a lo largo de toda la cadena de producción. 
De lo anteriormente expuesto, para la investigadora, las empresas grandes pueden influir en la actuación de sus empresas proveedoras, por ello, la responsabilidad social externa no se limita a la empresa en sí misma, sino que abarca su cadena de suministro. Ejemplo, si se aplica al ámbito de la discapacidad, la empresa, en sus relaciones con proveedores, puede constituirse en una referencia clave, favoreciendo las relaciones comerciales con aquellas empresas que cumplan la normativa en materia de empleo de personas con discapacidad.

Asimismo, a juicio de la investigadora, la accesibilidad de productos y servicios ofrecidos por la empresa conllevará al necesario respeto del diseño por parte de los proveedores que formen parte de la cadena de elaboración del producto 0 servicio, de manera de comprometerlos con la empresa para el logro de los objetivos organizacionales a través del suministro de lo requerido.

\section{Comunidad}

Los esfuerzos de las empresas, según Martínez (2011) están siendo motivados por los beneficios económicos, los cuales, a su vez, conllevan a un mayor involucramiento con la sociedad. Esto incluye el incremento de las ventas, mejora en la moral de los empleados, refuerzo de la habilidad de competir en el mercado regional, como efectos de empleados calificados y el ser un "vecino predilecto" de la comunidad. Muchas empresas también reconocen la oportunidad y necesidad de destinar recursos privados hacia problemas sociales, supliendo el rol del gobierno en distintas áreas.

Desde esta perspectiva, para Brignardello (2013), propiciar desde una compañía, con diversos proyectos, la oportunidad de brindar oportunidades 0 cambiar las perspectivas de la comunidad, es notablemente enriquecedor para ambas partes. La empresa suma empatía, prestigio, reputación y un acercamiento muy enriquecedor a un stakeholder clave. La comunidad beneficiada directa $\mathrm{a}$ indirectamente, pueden transformar su realidad, tener otra visión.

Es por ello, que hoy en día, la empresa, sea cual sea su magnitud, debe involucrarse en el desarrollo social promoviendo o sumándose a diversas acciones que contribuyan a este objetivo. Sin embargo, agrega la autora citada, el sector privado por sí solo no puede desencadenar procesos sostenibles y profundos de transformación social, ya que no cuenta con los recursos necesarios para hacerlo.

Es ahí donde se hace clave la articulación con los diversos actores integrantes de la sociedad (sector público, sociedad civil, referentes sociales, instituciones académicas y otras empresas) en pos de un objetivo en común, donde se requiere la participación activa de todos, para promover acciones colectivas y políticas públicas que impulsen el bienestar social y desarrollo de la ciudadanía.

La comunidad, según la define Gómez (2013), es el medio social donde se desarrolla la organización. Por ello, mediante sus decisiones, la empresa debe proteger a la misma, promover su desarrollo y acrecentar su bienestar. Las mismas participan en programas de seguridad, ecología, salud o educación debido a que les interesa el bienestar de la comunidad. Como ciudadano comercial se disfruta de cierto grado de prestigio local, esto puede dar como resultado una legislación local más favorable. 
Ahora bien, según Fernández (2009), el compromiso con la comunidad se refiere a las diferentes acciones tomadas por la empresa para maximizar el impacto de sus contribuciones en dinero, tiempo, productos, servicios, influencias, administración del conocimiento y otros recursos dirigidos hacia las comunidades en las cuales opera.

Cuando estas iniciativas son diseñadas y ejecutadas en manera programada $y$ estratégicamente, no sólo se entrega un valor agregado a los receptores sino que, además, refuerzan la reputación de las empresas, sus marcas y productos en las comunidades locales donde ellas tienen intereses comerciales, así como en el resto del mundo.

Otra cuestión fundamental a considerar, afirma Brignardello (2013), son las etapas que deben atravesar estos programas cuyos impactos no son inmediatos, sino a mediano plazo y de difícil medición, lo que requiere un compromiso mayor por parte de todos los involucrados. Debe considerarse además, una escucha activa y revisión de objetivos durante todo el proceso y un plan de comunicación para transmitir en forma clara y transparente el accionar de la empresa.

En este sentido, acota esta autora, la inversión social debe ser útil, responsable, respetuosa y ética. Estos principios, deben estar presentes también al momento de, llegado el caso, reconocer errores y corregirlos como parte del aprendizaje que brinda toda acción de esta envergadura.

Asimismo, con ese valor adicional y la empatía que genera, la organización puede sortear las crisis de forma más eficiente y productiva. Esto implica, desde el criterio de esta autora, un verdadero win-win, un compromiso esencial e ineludible, que en su versión más eficaz, puede atravesar a todos los stakeholders de la empresa, donde la misma alcanza, sumada a una gestión amigable con el entorno, un trabajo sustentable en lo económico, social y ambiental, que es, hoy en día, cada vez más requerido por consumidores, inversores $y$ opinión pública.

Finalmente concluye, las acciones filantrópicas y asistencialistas pueden ser eficaces para resolver problemas urgentes, el gran desafío de una organización, que se vuelve esencial en la relación con la comunidad, es involucrarse en acciones a mediano y largo plazo, procurando generar un verdadero desarrollo social.

En virtud de lo expuesto, la investigadora entiende, el fin de la responsabilidad social externa es promover la creación de una ciudadanía corporativa global conciliadora de intereses sociales y comerciales, lo cual la diferencia claramente de la filantropía. De esta forma, al insertarse en las comunidades locales, las empresas influyen de manera obligatoria en ellas, de forma negativa o positiva; por ello, la responsabilidad social externa intenta orientar a éstas para que influyan positivamente en las comunidades.

Lo anteriormente descrito, a juicio de la investigadora, se materializa de diferentes formas: aumentando o creando puestos de trabajo; mejorando la educación de los escolares de las comunidades locales; con retribuciones económicas, culturales y ecológicas. Así, la RSE y comunidades tienen una estrecha relación, al ser ellas integrantes de la sociedad humana se convierten en el objeto sobre el cual actúa la empresa.

\section{Competidores}

Según Gómez (2013), los competidores son las opciones que los clientes o usuarios tienen para adquirir los bienes o servicios 
que necesitan. La competencia en el mercado debe ser leal y honesta. Por su parte, afirma Martínez (2011), las buenas relaciones con los competidores ayudan a prevenir guerras de precios y a elevar el nivel de competencia. La libre empresa no requiere que los competidores estén constantemente peleando entre sí, por el contrario, mediante la organización y operación de la sociedad es posible obtener una mejor cooperación de las empresas competidoras, es por esto que tienen un compromiso ineludible con la nación.

En este orden de ideas, Navarro (2012), afirma que los resultados de una buena relación y la debida importancia ante accionistas, empleados, consumidores, comunidad, proveedores y competidores se ve reflejada en una mejora de la imagen de la empresa ante la sociedad, la cual es recompensada por el cliente y mejora el ambiente laboral aumentando la motivación de los empleados.

En este contexto, Fernández (2009) considera, el entorno competitivo incentiva a las empresas para mejorar la calidad de sus productos y servicios así como para ajustar sus precios. La competencia se convierte entonces, en un estímulo clave para la innovación, el progreso tecnológico y la búsqueda de medios más eficientes de producción. En este orden, la responsabilidad social externa puede convertirse incluso en una herramienta más para que las empresas compitan en la búsqueda de clientes.

Visto así, según el autor citado, el beneficiario último de las políticas de defensa de la competencia es el consumidor. La eficiencia productiva que se logra en un contexto de competencia efectiva se traslada al consumidor en la forma de menores precios o de un aumento de la cantidad ofrecida de los productos, de su variedad y calidad, con el consiguiente incremento del bienestar del conjunto de la sociedad.

Ahora bien, para la investigadora, el juego limpio en el mercado debería ser un prerrequisito de la responsabilidad social externa de las empresas, ésta debería empezar también por la aplicación correcta de las normas de competencia, las cuales garantizan y maximizan el bienestar de los usuarios y consumidores.

Así las cosas, cuando las empresas toman conciencia de la importancia de su responsabilidad social como elemento que les ayuda a mejorar su reputación y el nivel de estima o reconocimiento por parte de sus grupos de interés, deben excluir de sus prácticas aquellas conductas anticompetitivas que perjudican a los consumidores, de manera de ser socialmente responsables.

\section{Gobierno}

En este ámbito, para Navarro (2012), la responsabilidad social externa es un proceso que incluye por ende la gestión de la actividad empresarial en su relación con los grupos de interés externos. Un proceso de gestión que también comporta un nuevo modelo de gestión de las externalidades empresariales en lo económico, social y medioambiental. El establecimiento de los límites o fronteras dentro de los cuales estos costos y beneficios han de gestionarse, es cuestión de estrategias empresariales, pero también afectas cada vez más a cuestiones de gobernanza.

Por otra parte, dice este autor, en la medida en que la responsabilidad social externa supone la aparición de nuevos retos y oportunidades que afectan al espacio 
público, se les plantea a los gobiernos la necesidad de definir una propuesta política en relación con estas cuestiones. Algunos roles que los poderes públicos pueden desempeñar a la hora de diseñar un entorno facilitador serían: en la contraposición voluntariedad-legislación; y en los roles de medidas concretas.

En referencia a la contraposición voluntariedad-legislación, Fernández (2010) afirma, en la consideración de la relación entre políticas públicas y la responsabilidad social externa hay un posible punto de partida que contempla a esta última como vinculada, en esencia, con la voluntariedad, siempre más allá de lo exigido por la legalidad.

Si se sostiene una visión y definición de la responsabilidad social externa como un modelo de gestión que afecta de manera integral y transversal a toda la actividad empresarial no sería posible hablar de regular un modelo de gestión, sino que se circunscribe la acción reguladora a aquellos aspectos que en un momento dado y en función de las políticas diseñadas, puedan necesitarlo.

Pero, asevera el autor citado, la discusión sobre la responsabilidad social externa, antes o después, acaba ligándose a las percepciones sobe riesgos y oportunidades de la globalización económica. La definición de esta responsabilidad, centrada en actividades y responsabilidades más allá de lo legislado, a veces corren el riesgo de ignorar este contexto.

Por otro lado, si se establece una obligatoriedad podría ocurrir que las empresas se ciñeran estrictamente a la ley, en lugar de avanzar, se produjera un estancamiento, un acomodamiento a la legislación, como ocurre con el gobierno corporativo. Finalmente, dice Fernández (2010), se piensa que se debe de regular lo mínimo, lo de control, lo imprescindible, lo que son valores generalmente aceptados, dejando al desarrollo de la voluntariedad de la empresa el que consiga sobre esos mismos elementos diferenciarse de sus competidores por lo que hace y por lo que gestiona mejor.

Ahora bien, en cuanto a los roles de medidas concretas del sector público en el fortalecimiento de la responsabilidad social externa, de acuerdo a Blanco (2010), serían cuatro (4) las categorías básicas con las que se podrían clasificar las iniciativas en el ámbito de la acción pública: obligar o regular, facilitar o fomentar, colaborar o aliarse y respaldar o promover. En su papel regulador, las diferentes instancias gubernamentales deben definir los estándares mínimos de actuación empresarial dentro del marco legal.

Afirma el autor, al facilitar o fomentar, las agencias del sector público deben desarrollar un papel catalizador, secundario o de apoyo. La noción de aliarse o colaborar es central en la responsabilidad social externa, la aplicabilidad del acuerdo es bien diversa: obtención de compromisos medioambientales; realización de foros de discusión, debate y difusión del conocimiento; mejorar la efectividad de políticas de cooperación al desarrollo; plataformas de diálogo multi-grupo de interés entre empresas, gobierno, sociedad civil, y sindicatos.

En cuanto al respaldo político y promoción por parte del sector público y la práctica de la responsabilidad social externa $y$, en particular, de las iniciativas que la ponen en práctica, configuran el cuarto rol de esta tipología. Esta promoción puede 
desarrollarse en diversas formas, en las cuales se incluyen: documentos oficiales de difusión pública; reconocimiento directo a los esfuerzos de organizaciones individuales, o consorcios, a través de premios 0 menciones; o el mismo efecto ejemplarizante que tienen las adjudicaciones públicas o las prácticas de gestión del sector público.

En virtud de lo descrito, para la investigadora, la relación de la empresa con el gobierno es compleja pero puede sintetizarse en la necesidad de colaborar con ellos para trabajar a favor de la comunidad; cumplir con sus deberes como organización y ofrecer su contribución en donde se requiera es su obligación. Así, la responsabilidad con el gobierno puede resumirse en el cumplimiento de las obligaciones fiscales y el apoyo a los planes de desarrollo de la comunidad.

\section{Medio ambiente}

Hoy día, muchas compañías líderes definen sus responsabilidades con el ambiente en procesos de participación con la comunidad $u$ organizaciones no gubernamentales, según lo acota Delgado (2013). Desde esta perspectiva, agrega este autor, las empresas deben cuidar el impacto de sus operaciones en el entorno: instalaciones, procesos, productos 0 servicios; la eliminación de desechos; mayor eficiencia, así como productividad, de todas sus tareas y recursos; prácticas para minimizar el desgaste de los recursos naturales que pudiesen afectar a futuras generaciones; iniciativas de reciclaje y manejo eficiente de la energía, las cuales son cada vez más frecuentes.

En este marco referencial, Gómez (2013) afirma, gran número de empresas, de varios sectores y áreas geográficas, han conocido el valor así como la ventaja competitiva proveniente de implementar iniciativas medio ambientales. Tales iniciativas se aplican en diferentes ámbitos, como la prevención de la polución, uso eficiente de energía, diseño medioambiental amigable, administración de la cadena de suministro, tecnología industrial y desarrollo sustentable. Las empresas líderes, agrega el autor citado, están integrando la responsabilidad sobre el medio ambiente como un valor central del negocio en todos los niveles de su operación.

Ahora bien, para Fernández (2009), muchos son los temas ambientales que han ido cobrando importancia sobre las prácticas corporativas, desde hace ya algunos años: el consumo de energía y agua, la cantidad de desperdicios sólidos producidos, radiación, uso de material reciclable, impacto ambiental sobre la cadena de producción, entre otros. La responsabilidad social externa de la empresa con el ambiente es, hoy, mucho más que iniciativas de reciclaje o de conservación de energía.

Ser una empresa ambientalmente responsable es considerar los impactos ecológicos que generan la producción y operación de la empresa; estas consideraciones, como prácticas integrales, van más allá de meras regulaciones gubernamentales, adquiriendo un matiz de concientización de las empresas, según lo asevera Martínez (2011). En este orden, Gómez (2013) asevera, globalmente, las empresas están considerando los beneficios de ser ecológicamente responsable, debido a que no es solo un compromiso con las futuras generaciones sino que a su vez genera un valor intrínseco y una ventaja competitiva, al ser ejecutada bajo un criterio estratégico. 
Al respecto, afirma el autor citado, los beneficios ambientales de la responsabilidad social externa, son: aumento del rendimiento económico-financiero, reducción de costos de producción a través de control de desechos, eficiencia en el uso de la energía, mejor calidad de productos, condiciones favorables en la manufacturación, estimulación de la innovación así como de la competitividad hacia creación y diseño de nuevos productos o servicios, procesos ambientales conscientes, al mismo tiempo aumenta la reputación e imagen de la marca. Sin importar el tamaño, sector o ubicación geográfica, la creatividad de las empresas en el desarrollo de prácticas ecoeficientes y conservación ha demostrado que la protección del medio ambiente es beneficiosa para todos.

Así entonces, asevera Calvo (2014), las empresas exitosas incorporan en su estrategia un conjunto de factores económicos, ambientales y sociales que, a la vez de mejorar la imagen de la firma ante la sociedad, contribuyen al incremento de su rentabilidad, pues son recompensadas por los mercados, de allí la importancia de la responsabilidad social externa como motor de la productividad y utilidades. Además, explican algunos mecanismos que llevan de esta responsabilidad a la mayor productividad.

De esta manera, a juicio de la investigadora, para las empresas es importante tomar en cuenta cada uno de los factores mencionados, para el beneficio de la sociedad en la cual se desarrolla y de la cual forma parte. Se debe entender la responsabilidad social externa como un área de mejora continua, por ello es recomendable que las empresas revisen constantemente sus acciones en este sentido, pues su valor es depreciable en tiempo debiéndose ajustar a cambios en el entorno y a las necesidades de los actores involucrados a lo largo de la cadena productiva.

\section{MÉTODO}

La investigación desarrollada es de tipo descriptiva, con diseño no experimental, de campo y transeccional. El universo de la investigación está conformado por las droguerías pertenecientes a la industria farmacéutica del estado Zulia-Venezuela, inscrita en la Cámara de Industriales del Estado Zulia, con un tiempo en el mercado de 20 años en adelante y cuya estructura física se encuentran en la zona de Maracaibo, entre las cuales se encuentran: COBECA, FARVENCA, DRONENA y DROLANCA. Por las dimensiones que se pretenden estudiar la información se obtuvo de cuatro (4) gerentes de operaciones y cuatro (4) supervisores de despacho.

La recolección de la información se llevó a cabo a través de un cuestionario autoadministrada conformado por 18 ítems con un escalamiento de frecuencia con tres alternativas de respuestas, cuyas categorías fueron: siempre (3); algunas veces (2) y nunca (1). El cuestionario cual fue validado por el juicio de seis expertos y obtuvo un 0,913 de confiabilidad según el coeficiente Alfa Cronbach. La información fue procesada a través de la estadística descriptiva específicamente mediante la media aritmética, para la cual se diseñó un baremo de interpretación, reflejado en la Tabla 1 . 
Tabla 1. Categoría de análisis para la interpretación del promedio

\begin{tabular}{llll}
\hline Alternativas & Opción de respuesta & Rango para la media & Nivel de respuesta para la variable \\
\hline 3 & Siempre(S) & $2,35 \leq 3,00$ & Alta presencia/Fortaleza \\
2 & Algunas Veces (AV) & $1,68 \leq 2,34$ & Moderada presencia/Debilidad \\
1 & Nunca(N) & $1,00 \leq 1,67$ & Baja presencia/Debilidad \\
\hline
\end{tabular}

Fuente: La investigadora (2019)

\section{RESULTADOS}

Para dar respuesta al objetivo, identificar los grupos de interés de la responsabilidad social externa presentes en la industria farmacéutica del estado ZuliaVenezuela, se consideró como aspectos medibles los consumidores, proveedores, comunidad, competidores, gobierno y medio ambiente.

Comenzando con el análisis de los resultados, se pudo conocer los mostrados en la tabla 2. Se aprecia una alta presencia de los grupos de interés de la responsabilidad social externa presentes en la industria farmacéutica del estado ZuliaVenezuela, de manera que las droguerías que forman parte de esta industria son responsables al momento de evaluar todos sus procesos de decisión así como sus efectos sobre los demás.

Tabla 2. Grupos de interés de la responsabilidad social externa

\begin{tabular}{|c|c|c|}
\hline INDICADOR & $\overline{\bar{X}}$ & CATEGORIA \\
\hline Consumidores & 2,76 & Alta presencia/fortaleza \\
\hline Proveedores & 2,87 & Alta presencia/fortaleza \\
\hline Comunidad & 1,70 & Moderada presencia/Debilidad \\
\hline Competidores & 2,78 & Alta presencia/fortaleza \\
\hline Gobierno & 2,60 & Alta presencia/fortaleza \\
\hline Medio Ambiente & 2,05 & Moderada presencia/Debilidad \\
\hline DIMENSIÓN & 2,46 & Alta presencia/fortaleza \\
\hline
\end{tabular}

Fuente: La investigadora (2019)

Según estos resultados, se logra identificar los grupos de interés que figuran con alta presencia en su RSE. Al respecto es importante considerar a criterio de la investigadora que, para quienes gestionan estas droguerías, la identificación de estos grupos es fundamental para definir e implementar la RSE proporcionando la pauta para pasar del diseño a la ejecución, y de la ejecución a la evaluación.
Este resultado, de alta presencia de la dimensión, valida en muy alto grado lo expuesto por Fernández (2009) cuando afirma, que el alcance de la RSE significa indagar ante quien es responsable la empresa, por ello, debe ser responsabilidad de la empresa evaluar todos sus procesos de decisión así como sus efectos sobre los demás. Ésta debe observar a clientes, distribuidores y proveedores, pues mantiene 
una estrecha relación con ellos. Además, también está relacionada con otro contexto denominado la comunidad, en la cual se incluyen los ciudadanos, gobierno y empresas competidoras.
En lo concerniente al detalle de cada uno de los indicadores utilizados, para medir la dimensión, de seguido se especifican los resultados obtenidos al respecto, mostrados en la tabla 3, la cual recoge el resultado de la dimensión y cada uno de sus indicadores.

Tabla 3. Indicadores de los grupos de interés de la responsabilidad social externa

\begin{tabular}{|c|c|c|c|c|}
\hline INDICADOR & № & ITEMS & $\bar{X}$ & CATEGORIA \\
\hline \multirow{5}{*}{ 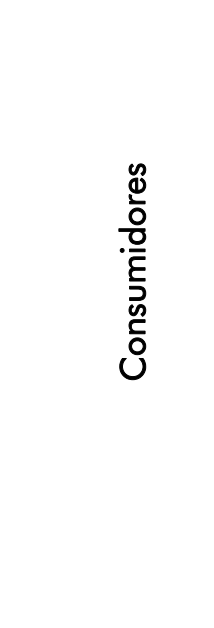 } & 1 & $\begin{array}{l}\text { Se considera que la prosperidad de sus } \\
\text { operaciones solo es posible si se satisface } \\
\text { eficazmente una necesidad social }\end{array}$ & 2,74 & $\begin{array}{l}\text { Alta } \\
\text { presencia/fortaleza }\end{array}$ \\
\hline & 2 & $\begin{array}{l}\text { Los productos que distribuyen están diseñados } \\
\text { pensando en que puedan ser utilizados por el } \\
\text { mayor número de personas posible, incluidos los } \\
\text { consumidores afectados por una discapacidad. }\end{array}$ & 2,77 & $\begin{array}{l}\text { Alta } \\
\text { presencia/fortaleza }\end{array}$ \\
\hline & 3 & $\begin{array}{l}\text { Establecen relaciones duraderas con sus clientes, } \\
\text { centrando su atención en la comprensión de sus } \\
\text { deseos. }\end{array}$ & 2,76 & $\begin{array}{l}\text { Alta } \\
\text { presencia/fortaleza }\end{array}$ \\
\hline & \multicolumn{2}{|c|}{ INDICADOR } & 2,76 & $\begin{array}{l}\text { Alta } \\
\text { presencia/fortaleza }\end{array}$ \\
\hline & 4 & $\begin{array}{l}\text { La relación con sus proveedores se caracteriza por } \\
\text { el cumplimiento. }\end{array}$ & 2,87 & $\begin{array}{l}\text { Alta } \\
\text { presencia/fortaleza }\end{array}$ \\
\hline \multirow{4}{*}{ 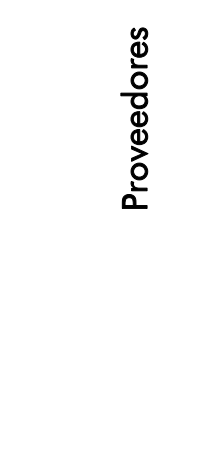 } & 5 & $\begin{array}{l}\text { La buena voluntad del proveedor es de capital } \\
\text { importancia cuando hay escasez de productos o } \\
\text { de mercancías }\end{array}$ & 2,88 & $\begin{array}{l}\text { Alta } \\
\text { presencia/fortaleza }\end{array}$ \\
\hline & 6 & $\begin{array}{l}\text { Los proveedores son parte fundamental de su } \\
\text { organización. }\end{array}$ & 2,86 & $\begin{array}{l}\text { Alta } \\
\text { presencia/fortaleza }\end{array}$ \\
\hline & \multicolumn{2}{|r|}{ INDICADOR } & 2,87 & $\begin{array}{l}\text { Alta } \\
\text { presencia/fortaleza }\end{array}$ \\
\hline & 7 & $\begin{array}{l}\text { Entrenan a sus empleados para que en sus } \\
\text { operaciones se respeten los valores o tradiciones } \\
\text { de la comunidad donde actúan. }\end{array}$ & 1,68 & $\begin{array}{l}\text { Moderada } \\
\text { presencia/Debilidad }\end{array}$ \\
\hline \multirow{3}{*}{ 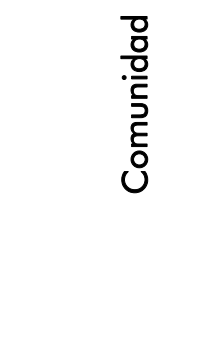 } & 8 & $\begin{array}{l}\text { Monitorean los impactos causados en la } \\
\text { comunidad por sus operaciones }\end{array}$ & 1,72 & $\begin{array}{l}\text { Moderada } \\
\text { presencia/Debilidad }\end{array}$ \\
\hline & 9 & $\begin{array}{l}\text { Se reconoce la comunidad en que está presente } \\
\text { como parte interesada importante en sus procesos } \\
\text { operacionales. }\end{array}$ & 1,69 & $\begin{array}{l}\text { Moderada } \\
\text { presencia/Debilidad }\end{array}$ \\
\hline & \multicolumn{2}{|c|}{ INDICADOR } & 1,70 & $\begin{array}{l}\text { Moderada } \\
\text { presencia/Debilidad }\end{array}$ \\
\hline
\end{tabular}




\begin{tabular}{|c|c|c|c|c|}
\hline INDICADOR & № & ITEMS & $\bar{X}$ & CATEGORIA \\
\hline \multirow{3}{*}{$\begin{array}{l}\stackrel{\circ}{\frac{1}{0}} \\
\stackrel{\frac{0}{0}}{0} \\
\stackrel{0}{0}\end{array}$} & 13 & $\begin{array}{l}\text { Sus operaciones son desarrolladas bajo el } \\
\text { cumplimiento de las obligaciones fiscales. }\end{array}$ & 2,58 & $\begin{array}{l}\text { Alta } \\
\text { presencia/fortaleza }\end{array}$ \\
\hline & 14 & $\begin{array}{l}\text { Las agencias del sector público han desarrollado } \\
\text { un papel de apoyo en el cumplimiento de su } \\
\text { responsabilidad social. }\end{array}$ & 2,62 & $\begin{array}{l}\text { Alta } \\
\text { presencia/fortaleza }\end{array}$ \\
\hline & 15 & $\begin{array}{l}\text { Las diferentes instancias gubernamentales } \\
\text { promocionan el cumplimiento de su } \\
\text { responsabilidad social. }\end{array}$ & 2,60 & $\begin{array}{l}\text { Alta } \\
\text { presencia/fortaleza }\end{array}$ \\
\hline \multirow{5}{*}{ 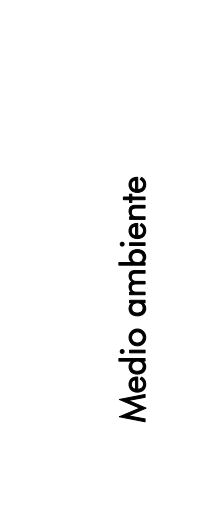 } & \multicolumn{2}{|c|}{ INDICADOR } & 2,60 & $\begin{array}{l}\text { Alta } \\
\text { presencia/fortaleza }\end{array}$ \\
\hline & 16 & $\begin{array}{l}\text { Son cuidadosos del impacto de sus operaciones en } \\
\text { el entorno }\end{array}$ & 2,06 & $\begin{array}{l}\text { Moderada } \\
\text { presencia/Debilidad }\end{array}$ \\
\hline & 17 & $\begin{array}{l}\text { Implementan iniciativas medio ambientales en sus } \\
\text { operaciones }\end{array}$ & 2,03 & $\begin{array}{l}\text { Moderada } \\
\text { presencia/Debilidad }\end{array}$ \\
\hline & 18 & $\begin{array}{l}\text { Integran la responsabilidad sobre el medio } \\
\text { ambiente como un valor central del negocio en } \\
\text { todos los niveles de su operación }\end{array}$ & 2,05 & $\begin{array}{l}\text { Moderada } \\
\text { presencia/Debilidad }\end{array}$ \\
\hline & \multicolumn{2}{|r|}{ INDICADOR } & 2,05 & $\begin{array}{l}\text { Moderada } \\
\text { presencia/Debilidad }\end{array}$ \\
\hline
\end{tabular}

Fuente: La investigadora (2019)

De esta forma, se evidencia alta presencia de los consumidores $(2,76)$, proveedores $(2,87)$, competidores $(2,78)$ y gobierno $(2,60)$, siendo considerados fortalezas de la RSE llevada a cabo. Sin embargo, señalan con mediana presencia lo referido a la comunidad $(1,70)$ y el medio ambiente $(2,05)$ lo cual indica debilidades, e implicando que se requieren mejoras al respecto.

De acuerdo a los valores obtenidos, relacionados con el indicador consumidores fue categorizado con alta presencia siendo una fortaleza de la RSE, con media de 2,76. Particularmente debe acotarse que todas las actividades medidas a través de los ítems aplicados para este indicador ostentan alta presencia, por ende, se convierten en fortalezas de su RSE en las droguerías objeto de estudio, validando así lo expuesto por Fernández (2009) quien afirma, la prosperidad de la empresa solo es posible si se satisface eficazmente una necesidad social, por ello se señala, claramente que el verdadero jefe de la empresa, el árbitro final de sus actos, es el consumidor.

En lo concerniente al indicador proveedores, los resultados indican una media de 2,87, ubicándola en una categoría de alta presencia siendo una fortaleza de la RSE de las droguerías bajo estudio, toda vez que cada uno de sus ítems arribó a la misma categoría. Esta situación valida la teoría expuesta por Gómez (2013), cuando afirma, los proveedores son parte fundamental de una organización, pues proporcionan insumos que hacen posible los procesos de intercambio (servicio) o la transformación (industria). Con ellos es básico establecer una relación formal, basada en la confianza y en el cumplimiento. 
Respecto al indicador comunidad, los resultados evidencia tanto en lo general como en lo especifico a través de sus ítems, moderada presencia con una media de 1,70 , otorgando a este grupo de interés de la RSE mediana presencia en las droguerías analizadas. Los resultados, de mediana presencia de este grupo de interés, son medianamente congruentes con lo expuesto por Gómez (2013) para quien, la comunidad es el medio social donde se desarrolla la organización, por ello, mediante sus decisiones, la empresa debe proteger a la misma, promover su desarrollo y acrecentar su bienestar.

Así las cosas, estas droguerías deben esforzarse por mejorar su compromiso en las diferentes acciones llevadas a cabo para maximizar el impacto en las comunidades en las cuales opera.

Seguidamente se observan los resultados del indicador competidores, cuyo valor es de 2,78 , producto de todas las actividades medidas a través de los ítems aplicados, indicando fortalezas de este grupo de interés en la RSE de las droguerías bajo estudio. Así entonces, se valida la posición teórica de Martínez (2011) cuando considera, las buenas relaciones con competidores ayudan a prevenir guerras de precios y a elevar el nivel de competencia; visto así, la libre empresa no requiere que los competidores estén constantemente peleando entre sí, al contrario, mediante la organización y operación de la sociedad es posible obtener una mejor cooperación de las empresas competidoras, por esto tienen un compromiso ineludible con la nación.

Respecto al indicador gobierno se muestra alta presencia, como parte de los grupos de interés de la RSE de estas droguerías, con una media de 2,60 como resultado de cada uno de las actividades medidas a través de sus ítems, ostentando alta presencia, lo cual indica fortalezas para su RSE. Dada la alta presencia de este grupo de interés, se alcanza coincidencia con lo expuesto por Navarro (2012) quien plantea que en la medida en que la responsabilidad social externa supone la aparición de nuevos retos y oportunidades que afectan al espacio público, se les plantea a los gobiernos la necesidad de definir una propuesta política en relación con estas cuestiones.

Finalmente, se analizó el indicador medio ambiente, cuyo valor de su media es de 2,05, dado que cada una de las actividades analizadas arrojó una moderada presencia, otorgándole una debilidad de este grupo de interés en la RSE de las droguerías analizadas. De manera que, según estos hallazgos moderadamente se aplica la teoría desarrollada por Calvo (2014), para quien las empresas exitosas deben incorporar en su estrategia un conjunto de factores económicos, ambientales y sociales que, a la vez de mejorar la imagen de la firma ante la sociedad, contribuyen al incremento de su rentabilidad, pues son recompensadas por los mercados, de allí la importancia de la responsabilidad social externa como motor de la productividad y utilidades.

Así las cosas, ante la debilidad que representa este indicador, estas droguerías deben considerar los impactos ecológicos que generan su producción y operación, a fin de ser ecológicamente responsable.

Lo mostrado permite afirmar que es importante tomar en cuenta cada uno de los grupos de interés mencionados, en beneficio de la sociedad en la cual se desarrolla y de la cual forma parte; por ello, deben entender la responsabilidad social externa como un área de mejora continua, lo cual las obliga a 
revisar constantemente sus acciones en este sentido, pues su valor es depreciable en tiempo debiéndose ajustar a cambios en el entorno y a las necesidades de los actores involucrados a lo largo de la cadena productiva.

\section{CONCLUSIONES}

Se identificaron los grupos de interés de la RSE presentes en presentes en la industria farmacéutica del estado Zulia-Venezuela, se encontró que estos grupos de interés ostentan alta presencia en la responsabilidad social externa que desarrollan las droguerías pertenecientes a esta industria. En específico, se evidenció alta presencia en su RSE de los consumidores, proveedores, competidores y gobierno. Mientras, ostentaron mediana presencia lo referente a la comunidad y medio ambiente, lo cual indica debilidades, e implicando que se requieren mejoras al respecto.

Así las cosas, las droguerías de la industria farmacéutica del estado ZuliaVenezuela que quieren tener éxito en sus operaciones comerciales deben tener como prioridad la consideración de la responsabilidad social empresarial dentro de su gestión, no solamente como un aspecto muchas veces exigido por las leyes de los países, sino como una conciencia transparente del impacto que causa cada industria al medio ambiente, a los recursos y a la sociedad en general.

De manera que, se debe fortalecer la presencia de algunos grupos de interés al momento de realizar las actividades referidas a la RSE, en especial la comunidad y medio ambiente. La idea es consolidar alta presencia para todos los grupos de interés de la RSE a fin de mejorar su imagen corporativa tanto con sus clientes, con sus colaboradores y también con sus proveedores que muchas veces las toman como modelos a seguir en estas prácticas.

Finalmente, cabe destacar que, la industria farmacéutica del estado Zulia está realizando pequeños avances en torno a la RSE; entendiendo el rol social implícito en este negocio, al ser proveedoras de soluciones a las necesidades de salud y bienestar de la sociedad, ya este compromiso obliga a las droguerías a mantener dentro de sus operaciones financieras o productivas, buenas relaciones con los grupos de interés de la RSE, como lo muestran los resultados de esta investigación.

\section{REFERENCIAS}

Blanco, M. (2010). Mediación y sistemas alternativos de resolución de conflictos. La responsabilidad social empresarial. Editorial Reus. Primera edición. España Brignardello, L. (2013). La relación con la comunidad: una cuestión esencial. Capacitarse. Centro de Educación Online Ejecutiva. Disponible en: http://www.cursosderse.com/2013/05/r elacion-con-la-comunidad-unacuestion-esencial/

Calvo, A. (2014). Fundamentos de la Unión Europea. Tercera edición. Editorial Centros de Estudios Ramón Areces. Madrid. España

Delgado, R. (2013). La responsabilidad social: compromiso voluntario. Disponible en: http://eleconomista.com.mx/columnas/ columnainvitadaempresas/2013/10/21 /responsabilidad-social-compromisovoluntario

Fernández, R. (2009). Responsabilidad social corporativa. Nueva cultura empresarial. Editorial Club Universitario.

España 
Fernández, R. (2010). Dimensiones de la responsabilidad social empresarial. Sus actores. Papel de las políticas públicas. Diario responsable. La RSE Global. Disponible en: http://diarioresponsable.com/opinion/1 1467-dimensiones-de-laresponsabilidadsocial-empresarial-susactores-papel-de-las-politicas-publicas

Fundación Escuela de Gerencia Social (FEGS). (2015). metodología para realizar un balance social. La responsabilidad social empresarial. Documento en línea. Disponible en: http://www.gerenciasocial.gob.ve/wwwr oot/es/ediciones-fegs

Gómez, H. (2013). Empresa internacionalizada y responsabilidad social: Un matrimonio convencido. Cuadernos Básicos. Publicaciones ICEX. España

González, L. (2010). Responsabilidad social empresarial en las PYMES. Revista Venezolana de Gerencia Vol.16. № 52. Universidad del Zulia. Maracaibo. Venezuela
Libro Verde de la Comunidad Económica Europea (2001). Disponible en: http://eurlex.europa.eu/legalcontent/ES/TXT/? uri =CELEX\%3A52001 DC0366

Machado, C., Berti, Z. y Caraballo, L. (2012): Balance social en la empresa venezolana.

Martínez, H. (2011). Responsabilidad social y ética empresarial. lera edición. Ediciones ECOE. Bogotá. Colombia

Modelo de la Fundación Escuela de Gerencia Social. Venamcham-FEGS. Venezuela.

Navarro, F. (2012). Responsabilidad Social Corporativa: Teoría y práctica. ESIC Editorial. Segunda Edición. Madrid. España

Rivera, C. (2015). Responsabilidad Social Empresarial en Venezuela. Disponible en:

http://venezuelaverde.com/responsabili dad-social-empresarial/ 